\title{
Detaillierte Gliederung
}

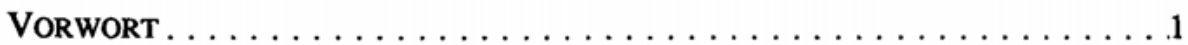

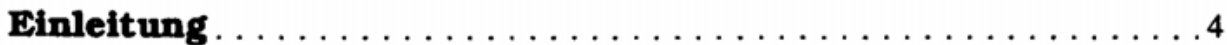

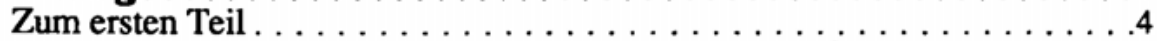

Karl Gottlieb Pfander und Rahmatullâh ibn $\underline{\text { Halil }}$ al- 'CUțânî al-

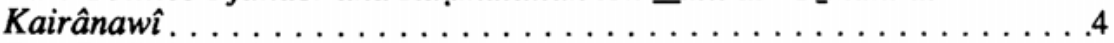

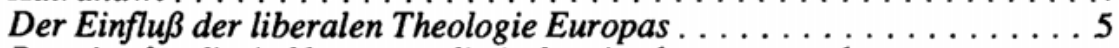

Beweise für die Anklagen muslimischer Apologeten aus der

europäischen liberalen Theologie . . . . . . . . . . . . . . . . . 7

Die Schriftverfälschung als Hauptthema der Kontroverse des

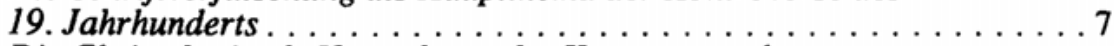

Die Christologie als Hauptthema der Kontroverse des

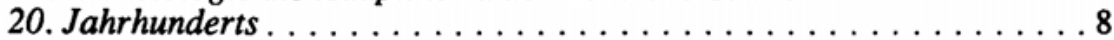

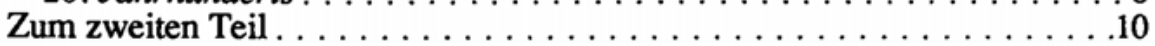

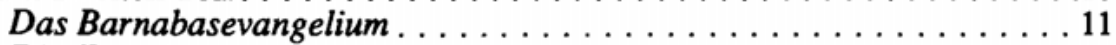

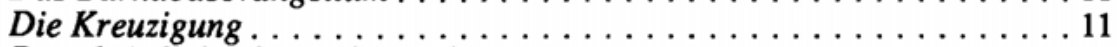

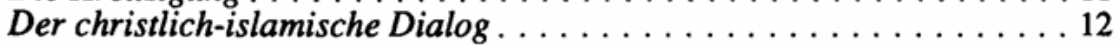

Ist eine objektive Darstellung der christlich-islamischen

Kontroverse möglich? . . . . . . . . . . . . . . . . . . . . . . 14

Einige Beispiele der christlich-muslimischen Kontroverse . . . . . . 16

Teil 1: Die Auseinandersetzung um Karl Gottlieb Pfanders 'mîzân al-haqq' und Rahmatulị̂̂h ibn Hạî̉ al- Uțmânî al-Kairânawî́s 'izhâr al-ḥaqq' $\ldots \ldots \ldots \ldots \ldots \ldots \ldots \ldots \ldots$

Kapitel 1: Die Auseinandersetzung um Karl Gottlieb Pfanders Streitschrift gegen den Islam 'mîzân al-ḥaqq' . . . . . 18

EINIGE BEISPIELE DER CHRISTLICH-ISLAMISCHEN BEGEGNUNG BIS ZUM

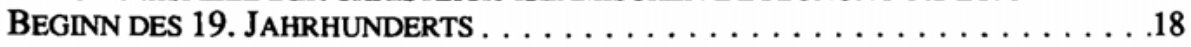

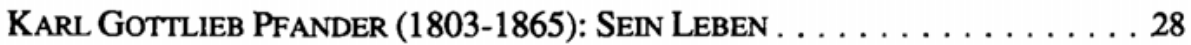

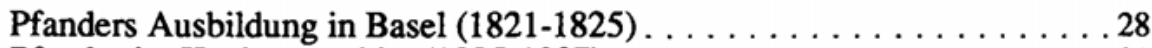

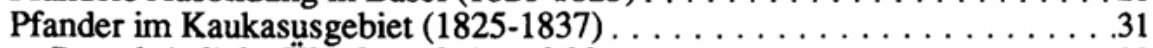

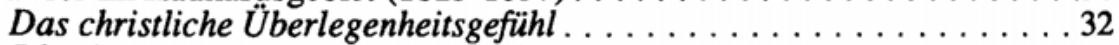

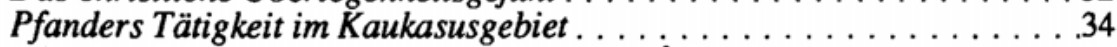

Pfanders Dispute mit einigen muslimischen culamâ ${ }^{\prime} \ldots \ldots \ldots \ldots \ldots . \ldots \ldots$

Pfanders Orientbild . . . . . . . . . . . . . . . . . . . . . . . . . . 37

Das Ende der Arbeit im Kaukasusgebiet . . . . . . . . . . . . . 38

Die Ergebnisse der Arbeit . . . . . . . . . . . . . . . . . . . . . . . . . . .39

'mîzân al-haqq' - 'Die Waage der Wahrheit' . . . . . . . . . . . . . 40

Der Wechsel zur Church Missionary Society . . . . . . . . . . . . . .41

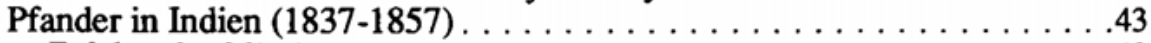

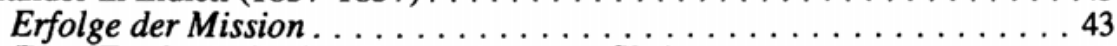

Erste Taufen indischer Konvertiten zum Christentum . . . . . . 45

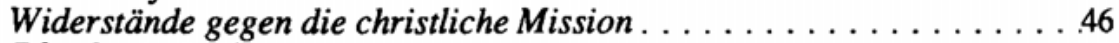

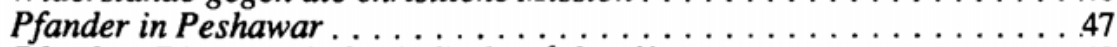

Pfanders Dispute mit den indischen Gulamâ' . . . . . . . . . . . . .49

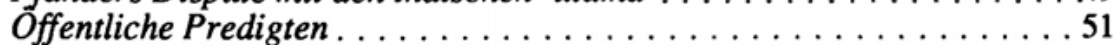

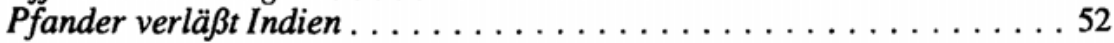


Das Osmanische Reich Ende des 19. Jahrhunderts . . . . . . . . . . . . 53

Pfander in Konstantinopel (1858-1865) . . . . . . . . . . . . . . . 55

Taufen in Konstantinopel . . . . . . . . . . . . . . . . . . . . 56

Spannungen in Konstantinopel . . . . . . . . . . . . . . . . . . .57

Sir Henry Bulwer und das Ende der protestantischen

Missionsarbeit in Konstantinopel . . . . . . . . . . . . . . . 58

Pfanders Rückkehr nach England . . . . . . . . . . . . . . 63

Pfanders Tod . . . . . . . . . . . . . . . . . . . . . . . . . . . 64

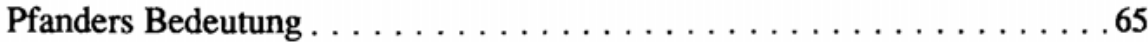

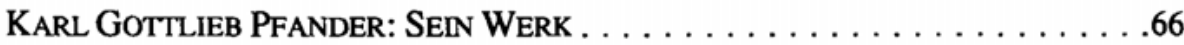

Pfanders Werke außer 'mîzân al-haqq' . . . . . . . . . . . . . . . . . 66

Pfanders Hauptwerk: 'mîzân al-hạq' . . . . . . . . . . . . . . . . . . . . . . 69

'mîzân al-haqq': Seine Bedeutung . . . . . . . . . . . . . . 69

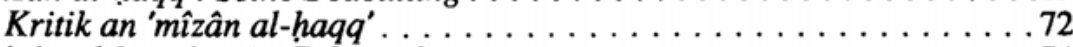

'mîzân al-haqq': sein Gebrauch . . . . . . . . . . . . . . . . . . . 74

Revisionen und Übersetzungen - Die Geschichte des Werkes . . . . . . . 76

Das Original 1829. . . . . . . . . . . . . . . . . 76

Armenisch 1831/Aserbaidschanisch $1832 \ldots \ldots \ldots \ldots$

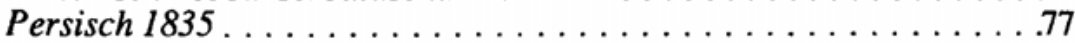

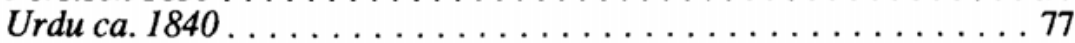

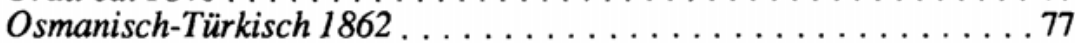

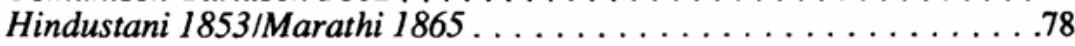

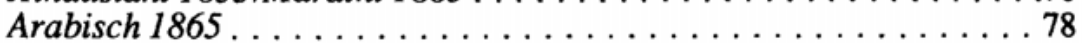

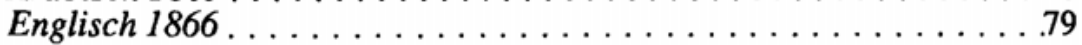

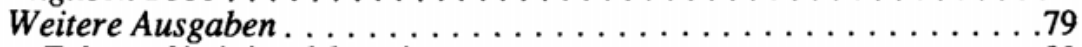

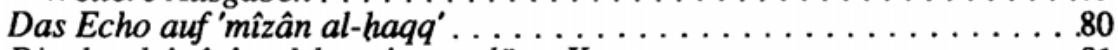

Die durch 'mîzân al-haqq' ausgelöste Kontroverse . . . . . . . . . . 81

Der Anlaß zur Abfassung von 'mîzân al-haqq' . . . . . . . . . . . 82

Der Charakter des Werkes . . . . . . . . . . . . . . . . .83

Pfanders Selbstverständnis . . . . . . . . . . . . . .83

Die äußerliche Anpassung des Werkes . . . . . . . . . . . .85

Der Stil. . . . . . . . . . . . . . . . . . . . 85

Das Gespräch mit dem Leser . . . . . . . . . . . . . . . . . . . . 87

Pfanders theologischer Standpunkt . . . . . . . . . . . 87

Die Absolutheit Pfanders . . . . . . . . . . . . . . . . . . .89

Der Maßstab der Wahrheitsfindung in 'mîzân al-haqq' . . . . . . . . . . 90

Der Verstand . . . . . . . . . . . . . . . . . . . . . . . . . . . .

Der Titel des Werkes . . . . . . . . . . . . . . . .92

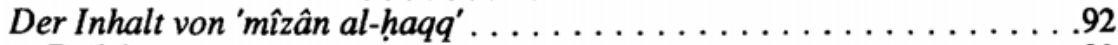

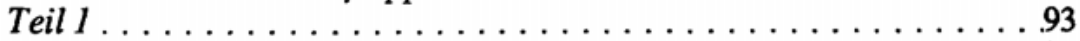

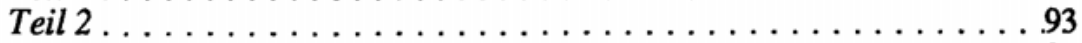

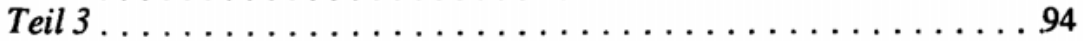

Vier Beispiele aus dem Inhalt von 'mîzân al-haqq' . . . . . . . . . . . 94

Wurde der Text der Bibel verfälscht? . . . . . . . . . . . . 95

Ist der Koran von Gott inspiriert? . . . . . . . . . . . . . .97

Gibt es eine Trinität? . . . . . . . . . . . . . . . 99

Ist Muhammad der von Gott gesandte Prophet? . . . . . . . . . . 100 


\section{Kapitel 2: Die Auseinandersetzung um Rahmatullâh ibn Haîn al- Uțmânî al-Kairânawîs Streitschrift gegen das \\ Christentum 'ị̣hâr al-ḥaqq'}

AL-KAIRÂNAWî ALS MUSLIMISCHER APOLOGET INDIENS IM 19.

JAHRHUNDERT .

Das islamische Indien

Europäische Kolonialmächte in Indien

Das Christentum in Indien

Die Quellenlage zu Leben und Werk al-Kairânawîs

RAḤMATULLÂH IBN HEALîL AL- CUTMÂNî AL-KAIRÂNAWÎ (1818-1891):

SEIN LEBEN .

Die Familie al-Kairânawîs . . . . . . . . . . . . . . . . . . . . . . . . . . 109

al-Kairânawîs Reaktion auf die christliche Mission . . . . . . . . . . . . . 110

Muhammad Wazîr Hân . . . . . . . . . . . . . . . . . . . . . . 111

al-Kairânawî in Mekka .

'izhâr al-haqq' - 'Die Aufdeckung der Wahrheit' . . . . . . . . . . . . . . . 113

Die Begegnung zwischen Pfander und al-Kairânawî

Die Vorgeschichte der Agra-Debatte 1854.

Zwei muslimische Schriften im Vorfeld der Debatte . . . . . . . . . . . 116

Sayyid Muhammad Hâdî: 'kašf al-astâr' $1845 \ldots \ldots \ldots$. . . . . . 116

'Alî Hasan: 'kitâb-i istifsâr' 1845/1846 . . . . . . . . . . . . . .116

Die öffentliche Kontroverse in Lucknow 1848 . . . . . . . . . . . . 118

Weitere muslimische Streitschriften gegen die christliche Mission . . .120

al-Kairânawîs Herausforderung an die christlichen Missionare

zur öffentlichen Diskussion . . . . . . . . . . . . . . . . . . . 120

Der Verlauf der Debatte in Agra 1854 . . . . . . . . . . . . . . . . 122

Der 1.Tag . . . . . . . . . . . . . . . . . . . 124

Der 2.Tag . . . . . . . . . . . . . . . . . . . 125

Muslimische Berichte über die Debatte . . . . . . . . . . . . . 126

Christliche Berichte über die Debatte . . . . . . . . . . . . . . . . . 129

Die Bedeutung Agras für die Kontroverse . . . . . . . . . . . . . . . . 129

Die Bedeutung der europäischen Theologie für die Kontroverse . . . . . . 130

Konversionen zum Christentum als Folge der Debatte . . . . . . . . . . . 132

Die 'Meuterei' im britischen Indien 1857 . . . . . . . . . . . . . . . . . . . . . 133

Gründe für die 'Mutiny' . . . . . . . . . . . . . . . . . . . . . . . . . . . . 134

Die Niederschlagung des Aufstandes . . . . . . . . . . . . . . . . . 136

Die Bedeutung der 'Meuterei' für die Missionare . . . . . . . . . . . . . . . . 139

War al-Kairânawî an der Erhebung beteiligt? . . . . . . . . . . . . . . . 140

al-Kairânawîs Reisen nach Konstantinopel . . . . . . . . . . . . . . . . . 142

RAḤMATULLÂH IBN HALẤl AL- UTMÂNî AL-KAIRÂNAWî: SEIN WERK . . . . . . 144

al-Kairânawîs Werke außer 'izhâr al-haqq': . . . . . . . . . . . . . . . . . 144

al-Kairânawîs Hauptwerk: 'izhâr al-ḥaqq' . . . . . . . . . . . . . . . . . 146

'izhâr al-haqq': Seine Bedeutung . . . . . . . . . . . . . . . . 146

Muhammad Rašî̀ Ridâs Rückgriff auf 'iẓhâr al-haqq' . . . . . . . . . 148

'iżhâr al-haqq' als Vorbild für die muslimische Apologetik . . . . . . . 149

Der Gebrauch von 'izhâr al-haqq' . . . . . . . . . . . . . . . . . . . . . . . 149

Revisionen und Übersetzungen-Die Geschichte des Werkes . . . . . . 151

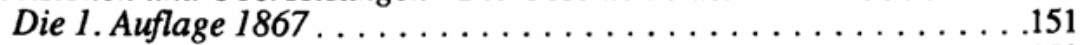

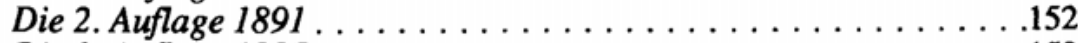

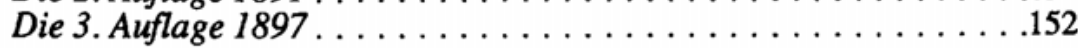




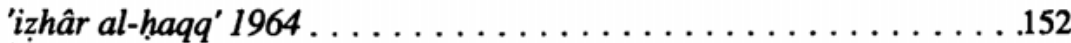

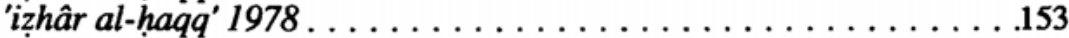

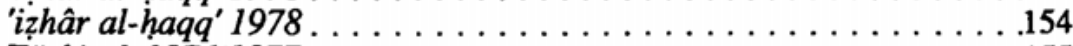

Türkisch 1876/1877. . . . . . . . . . . . . . . . . . . . . . . .155

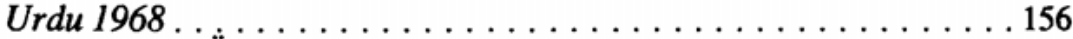

Europäische Übersetzungen . . . . . . . . . . . . . . . . . . . . 157

Französisch 1880 . . . . . . . . . . . . . . . . . . . . . . . 157

Das Vorwort zur Französischen Ausgabe . . . . . . . . . . . . 158

Englisch nach $1900 \ldots \ldots \ldots$. . . . . . . . . . . . . . . . . 160

Gujarati ca. 1900 . . . . . . . . . . . . . . . . . . . . . . . 162

Die Abfassungszeit der englischen und der Gujarati-Ausgabe . . . . 163

Die neueste Auflage von 'izhâr al-haqq' 1989 . . . . . . . . . . . . 164

Das Echo auf 'izhâr al-haqq' . . . . . . . . . . . . . . 165

Der Anlaß zur Abfassung von 'izhâr al-haqq' . . . . . . . . . . 166

Der Charakter des Werkes . . . . . . . . . . . . . . . . . . . . . . 167

Der Verstand . . . . . . . . . . . . . . . . . . . . . . . . . . . . . 169

al-Kairânawîs Gebrauch christlich-theologischer Werke . . . . . . 170

Die Absolutheit al-Kairânawîs . . . . . . . . . . . . . . . 171

al-Kairânawîs theologischer Standpunkt . . . . . . . . . . . . . 171

Der Maßstab zur Wahrheitsfindung in 'izhâr al-haqq' . . . . . . . . 172

Der Inhalt von 'izhâr al-haqq' . . . . . . . . . . . . . . . . . . . . 174

Der 1. Teil . . . . . . . . . . . . . . . . . . . . . . . . 174

Das 1. Buch . . . . . . . . . . . . . . . . . . . . . . 174

Das 2. Buch . . . . . . . . . . . . . . . . . . . . 175

Das 3. Buch . . . . . . . . . . . . . . . . . . 175

Das 4. Buch. . . . . . . . . . . . . . . . . . . 175

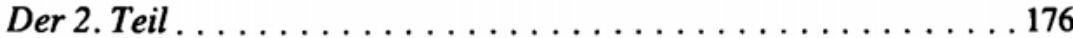

Das 5. Buch . . . . . . . . . . . . . . . . . . 176

Das 6. Buch . . . . . . . . . . . . . . . . . . . . . 176

al-Kairânawî erweitert die Vorwürfe früherer Apologeten . . . . . . 177

Vier Beispiele aus dem Inhalt von 'izhâr al-haqq' . . . . . . . . . . 177

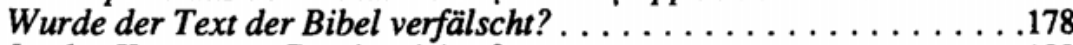

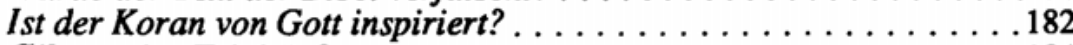

Gibt es eine Trinität ? . . . . . . . . . . . . . . . . 184

Ist Muhammad der von Gott gesandte Prophet? . . . . . . . 186

Kapitel 3: Die Fortsetzung der Kontroverse mit Schriften gegen Karl Gottlieb Pfanders 'mîzân al-haqq' . . . . . . . . . . . 189

DIE CHRISTLICH-MUSLIMISCHE KONTROVERSE DES 19. JAHRHUNDERTS . . . . . 189

Muslimische Apologeten zur Schriftverfälschung . . . . . . . . . . .189

Sayyid Ahmad Khâns Verhältnis zum Christentum . . . . . . . . . 190

Der Rückgriff muslimischer Apologeten auf die europäische

Theologie und Philosophie des 19. Jahrhunderts . . . . . . . . . . 191

Sir William Muir . . . . . . . . . . . . . . . . . . . . . . . . . . 193

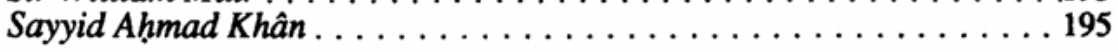

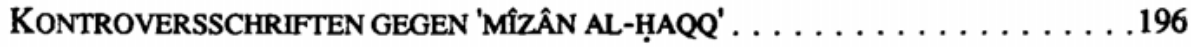

Ishâq Effendi: 'Sams al-haqq' $1862 \ldots \ldots \ldots \ldots \ldots \ldots \ldots \ldots \ldots \ldots \ldots$

Der Anlass zur Abfassung des Werkes . . . . . . . . . . . . . . . . . 197

Der Autor des Buches . . . . . . . . . . . . . . . . . . . . . . . . 197

Der Inhalt von 'šams al-haqq' . . . . . . . . . . . . . . . . . 198

'šams al-haqq' als persönlicher Angriff auf Pfander . . . . . . . 200 
Pfanders Reaktion auf'šams al-haqq' . . . . . . . . . . . . 201

Pfanders Antwort auf'šams al-haqq' . . . . . . . . . . . . . . .203

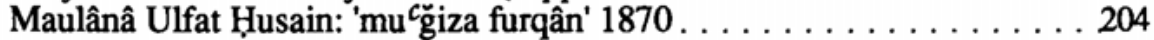

Muhammad Abû al-Manşûr: 'mîzân al-mîzân' $1878 \ldots \ldots \ldots \ldots \ldots$. . . . 205

'Alî b. 'Abd Allâh al-Bahrânî: 'lisân aş-şidq' 1889/1890 . . . . . . . . . . 205

'Abd ar-Rahmân al-Gazîrî: 'adillat al-yaqîn ...' $1934 \ldots \ldots \ldots \ldots \ldots .208$

al-Gazîrîs Widerlegung von Pfanders 'mîzân al-haqq' . . . . . . 208

al-Gazîrîs Rückgriff auf die liberale europäische Theologie . . . . . . . 209

\section{Kapitel 4: Die Fortsetzung der Kontroverse mit Schriften} gegen Rahmatullâh ibn Hiẩi al- Utmânî al-Kairânawîs

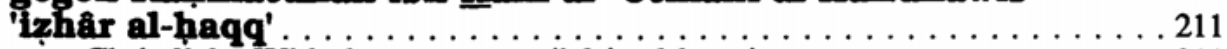

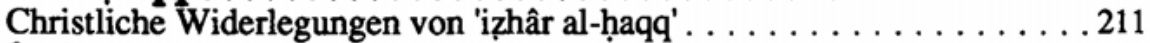

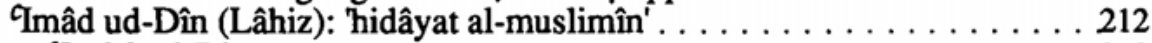

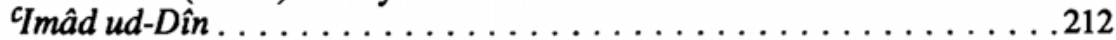

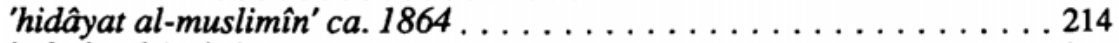

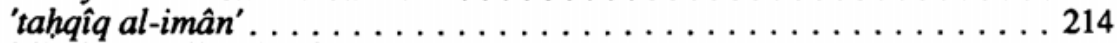

Mit den Waffen des Gegners . . . . . . . . . . . . . . . . . . . 215

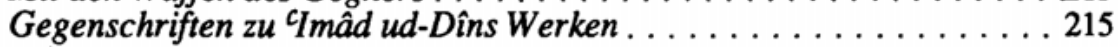

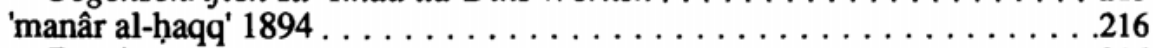

Der Autor . . . . . . . . . . . . . . . . . . . . . . . 216

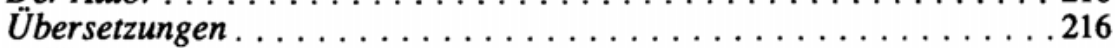

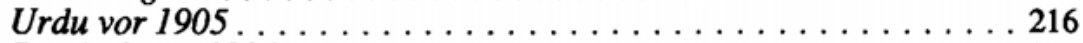

Persisch vor $1904 \ldots \ldots$. . . . . . . . . . . . . . . . . . . . . 217

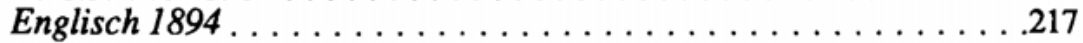

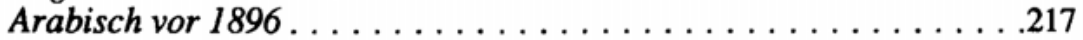

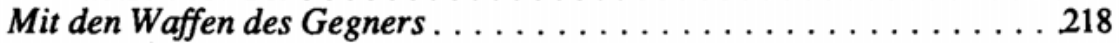

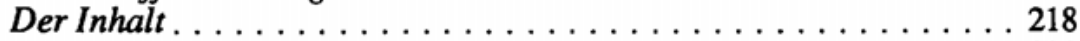

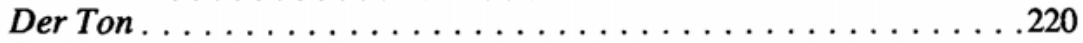

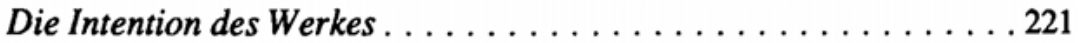

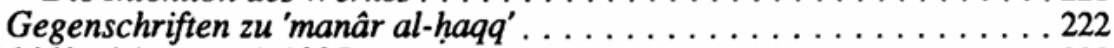

'al-hidâya' (anonym) $1895 \ldots \ldots \ldots \ldots \ldots \ldots \ldots \ldots \ldots \ldots \ldots \ldots \ldots \ldots \ldots \ldots .222$

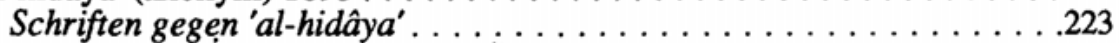

Niqûlâ Ya'qûb Gibrîl: 'abhâât al-muğtahidîn ...' $1901 \ldots \ldots \ldots \ldots \ldots .223$

Der Ton . . . . . . . . . . . . . . . . . . . . . . . . . . . .224

Die Adressaten des Werkes . . . . . . . . . . . . . . . . . . . . . . 224

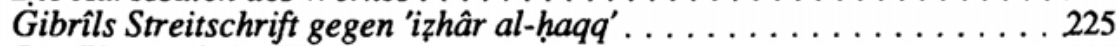

Die Thematik des Werkes . . . . . . . . . . . . . . . . . . .225

Die Rolle des Verstandes . . . . . . . . . . . . . . . . . . . . .226

Gibrîls theologischer Standpunkt . . . . . . . . . . . . . . . . . . 227

Die Waffen des Gegners . . . . . . . . . . . . . . . . . . . . . . 227

Schriften gegen Gibrîls 'abhât al-muğtahidîn' . . . . . . . . . . . .227

'mîzân al-haqq': W. St. C. Tisdalls Überarbeitung $1910 \ldots \ldots \ldots \ldots \ldots .228$

'mîzân al-haqq' 1910 als Reaktion auf 'izhâr al-haqq' . . . . . . . . . 228

William St. C. Tisdall über 'izhâr al-haqq' . . . . . . . . . . . 230

Der Gebrauch islamischer Quellen . . . . . . . . . . . . . . . .231

Die Qualität der Überarbeitung . . . . . . . . . . . . . . . . 2231

Der Vorwurf des Kolonialismus . . . . . . . . . . . . . . . . . . 232

Der Stil . . . . . . . . . . . . . . . . . . . . . . . 233

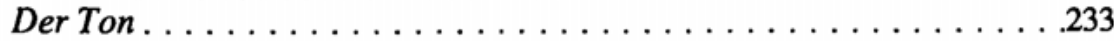

Das Gespräch mit dem Leser . . . . . . . . . . . . . . . . . . . . 233

Die Aktualisierung des Werkes . . . . . . . . . . . . . . . 234 
Tisdalls Beitrag zur christlich-islamischen Kontroverse . . . . . . . .234

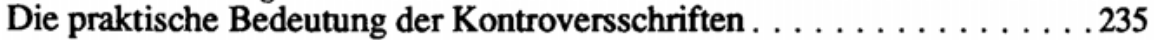

Zusammenfassung der Ergebnisse in Thesen: Die christlich-muslimische Kontroverse des 19. Jahrhunderts . . . . . . 238

Teil 2: Die Diskussion über das Barnabasevangelium . . . . . 241

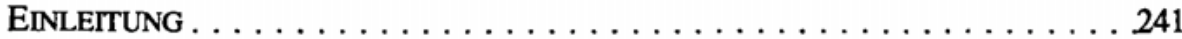

Kapitel 1: Barnabasschriften in der Kirchengeschichte . . . . . 244

Barnabas-Literatur vom 2. bis 8. Jahrhundert n. Chr. . . . . . . . . . . 244

Der Barnabas-Brief . . . . . . . . . . . . . . . . . . . . . . . . 244

Die Barnabas-Akten . . . . . . . . . . . . . . . . . . . . . . 245

Der 'Codex Barocci 39' . . . . . . . . . . . . . . . . . . . . .245

Das 'Gelasius-Dekret' . . . . . . . . . . . . . . . . . . .246

Die 'Liste (das 'Verzeichnis') der 60 Kanonischen Bücher' . . . . . . . . 246

Das italienische Manuskript des Barnabasevangeliums . . . . . . . . . 247

Der Inhalt des Barnabasevangeliums nach dem italienischen

Manuskript . . . . . . . . . . . . . . . . . . . . . . . 247

Bibel und Koran im Barnabasevangelium . . . . . . . . . . . . . . 248

Barnabas. . . . . . . . . . . . . . . . . . . . . . . . . .248

Muhammad . . . . . . . . . . . . . . . . . . . . . . 249

Jesus Christus . . . . . . . . . . . . . . . . . . . . . . . . . . . . . . . . 249

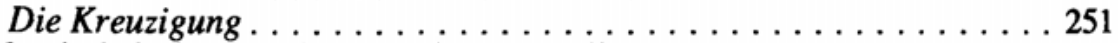

'Islamische' Elemente im Bamabasevangelium . . . . . . . . . . . .253

Die Schrift . . . . . . . . . . . . . . . . . . . . . ..253

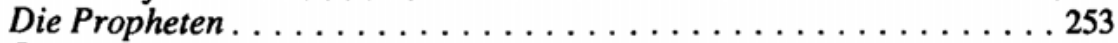

Jesus. . . . . . . . . . . . . . . . . . . . . . . . .254

Das Barnabasevangelium widerspricht dem Koran $\ldots \ldots \ldots \ldots \ldots 255$

Jesus . . . . . . . . . . . . . . . . . . . . . . . ..255

Der Himmel . . . . . . . . . . . . . . . . . . . . . . . . . ..255

Die Ehe . . . . . . . . . . . . . . . . . . . .256

Objektive Fehler im Barnabasevangelium $\ldots \ldots \ldots \ldots \ldots \ldots \ldots 256$

Geographie. . . . . . . . . . . . . . . . . . . .256

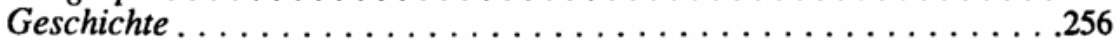

Anhaltspunkte für eine mittelalterliche Abfassungszeit? . . . . . . 257

Dante Alighieri . . . . . . . . . . . . . . . . . . . . . . . . . . . 257

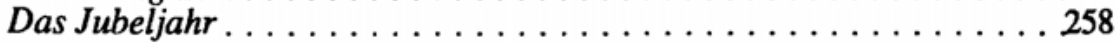

Die Askese . . . . . . . . . . . . . . . . . . . . . . .258

Die Vulgata . . . . . . . . . . . . . . . . . . . . .258

Das Fasten . . . . . . . . . . . . . . . . . . . . . . . 259

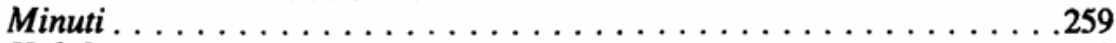

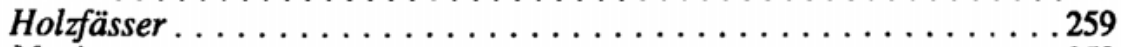

Maria .............................259

Das Gebet . . . . . . . . . . . . . . . . . . . 259

Das Paradies. . . . . . . . . . . . . . . . . . . . . .260

Mögliche Textvorläufer des Barnabasevangeliums . . . . . . . 260

Das spanische Manuskript des Barnabasevangeliums . . . . . . . 260

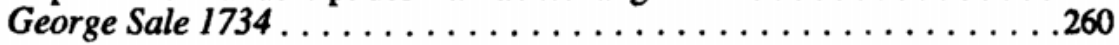




\section{Kapitel 2: Die Geschichte der Rezeption des Barnabas-}

evangeliums bis zum Erscheinen der arabischen Edition . . . . .263

DAS BARNABASEVANGELIUM BIS ZUR ERSTEN GESAMTEDITION 1907 . . . . . . 263

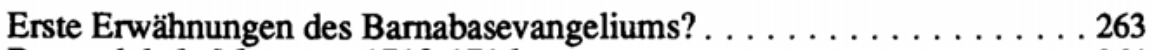

Bernard de la Monnoye $1713-1716 \ldots \ldots \ldots \ldots \ldots \ldots \ldots \ldots . \ldots \ldots$

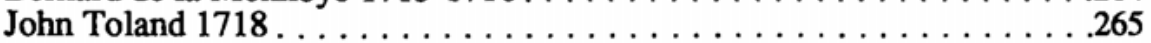

'Christianity not mysterious' $1696 \ldots \ldots \ldots \ldots \ldots \ldots \ldots \ldots \ldots$

'Nazarenus' 1718 ............................265

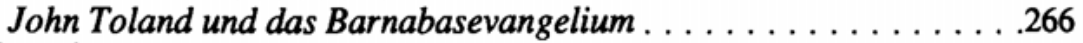

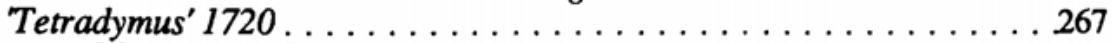

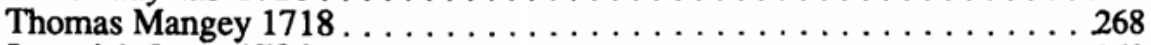

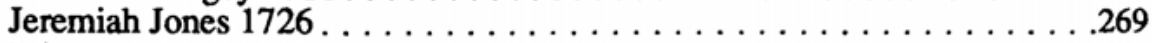

Johann Albert Fabricius $1703 / 1719 / 1738 \ldots \ldots \ldots \ldots \ldots \ldots \ldots .270$

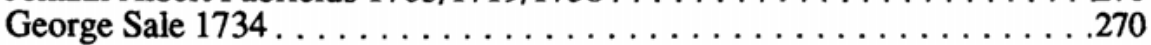

Joseph White $1784 \ldots \ldots \ldots \ldots \ldots \ldots \ldots \ldots \ldots \ldots \ldots \ldots \ldots \ldots .272$

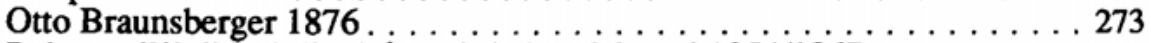

Rabmatullâh ibn Halîl al-CUtmânî al-Kairânawî 1854/1867 . . . . . . . . . 274

Wie kam das Barnabasevangelium in die islamische Welt? . . . . . . . 274

Das Barnabasevangelium in der Gujarati-Ausgabe von

al-Kairânawîs 'izhhấr al-haqq' ca. $1900 \ldots \ldots \ldots \ldots \ldots \ldots . \ldots . \ldots 276$

Das Barnabasevangelium in Indien vor $1900 \ldots \ldots \ldots \ldots \ldots \ldots \ldots .277$

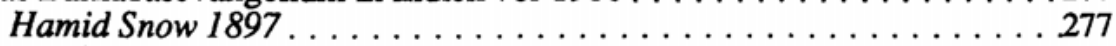

Textfragmente des Barnabasevangeliums bei Hamid Snow . . . . . . . .279

William E. A. Axon 1902 . . . . . . . . . . . . . . . . . . . . . 281

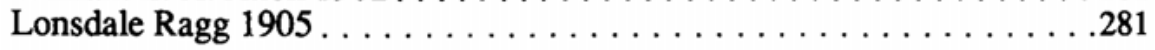

LONSDALE AND LAURA RAGGS ENGLISCHE EDITION DES

BARNABASEVANGELIUMS $1907 \ldots \ldots \ldots \ldots \ldots \ldots \ldots \ldots \ldots 28 \ldots \ldots \ldots$

Der Anla $\beta$ für die Erstellung der englischen Edition . . . . . . . . 282

Die englische Edition des Barnabasevangeliums - ein Instrument

der Apologetik . . . . . . . . . . . . . . . . . . . . . . . . . 284

\section{Kapitel 3: Muhammad Rašîd Rị̣̂as arabische Edition des}

Barnabasevangeliums $\ldots \ldots \ldots \ldots \ldots \ldots \ldots \ldots \ldots \ldots \ldots$

Muhammad Rašid Riḍ̂a : Sein Leben und Werk . . . . . . . . . . . . . 286

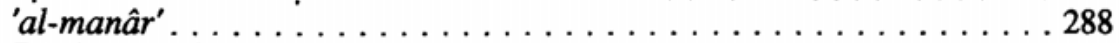

Die 'manâr-Schule' . . . . . . . . . . . . . . . . . . .290

Der 'tafsîr al-qur'ân al-hakîm' . . . . . . . . . . . . . . . 291

Rašîd Ridâs 'fatwấ'-Sammlung . . . . . . . . . . . . . . . . . . 293

Rašìd Ridâs Rückgriff auf die historisch-kritische Methode . . . . . . . 293

Das Barnabasevangelium in 'al-manâr' . . . . . . . . . . . . . 295

Das Barnabasevangelium im 'tafsîr al-qur'ân al-hakîm' . . . . . . . . . . 296

Muhammad Rašîd Riḍ̂̂ Rückgriff auf Rahmmatullâh ibn $\underline{\text { Halil }}$

al-CUtmânî al-Kairânawî̀ . . . . . . . . . . . . . . . . . . . . . . . .296

Die Frage der Erlösung und Kreuzigung im 'tafsîr' . . . . . . . . . . . .297

Raŝîd Riḍ̂âs arabische Edition des Barnabasevangeliums 1908 . . . . . . . .299

$\underline{\text { Halil }}$ Sa $a^{c} \hat{d} d a s$ Vorwort zur arabischen Übersetzung des

Barnabasevangeliums . . . . . . . . . . . . . . . . . . . . . 300

Rašî̀d Ridâs Vorwort zur arabischen Übersetzung des

Barnabasevangeliums . . . . . . . . . . . . . . . . . . . . . . 302 
DAS BARNABASEVANGELIUM IN DER MUSLIMISCH-CHRISTLICHEN

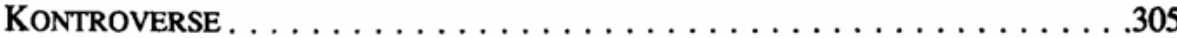

Schwerpunkte der Diskussion . . . . . . . . . . . . . . . 305

Ein christliches oder muslimisches Evangelium? . . . . . . . . . . 306

Das Barnabasevangelium in der modernen Kontroverse . . . . . . . . . 307

Das Barnabasevangelium ist das wahre Evangelium . . . . . . . . . . . 308

Die Schein-Echtheitsdiskussion . . . . . . . . . . . . . . . . . . . . . 309

Die Identifikation des heutigen Barnabasevangeliums mit

Barnabasevangelium-Fragmenten aus der Kirchengeschichte . . . . . . 310

Die Verknüpfung mit der 'Paraklet'-Diskussion . . . . . . . . . . . . 310

Das Barnabasevangelium heute . . . . . . . . . . . . . . . . 310

Beispiele für die Bedeutung des Barnabasevangeliums in der

apologetischen Auseinandersetzung heute . . . . . . . . . . . 311

CHRISTLICHE STELlungNAHMEN GEGEN DAS BARNABASEVANGELIUM . . . . . 314

Schriften zum Barnabasevangelium . . . . . . . . . . . . . . . . . . . . 314

William Henry Temple Gairdner und Selim 'Abd-ul-Ahad 1908 . . . . . 314

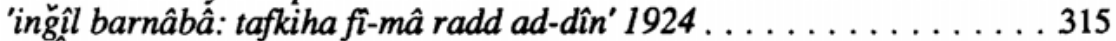

al-Âb Jûsif al-Haddâd $1964 \ldots \ldots$. . . . . . . . . . . . . . . . . . . 315

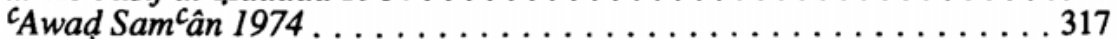

Jan Slomp $1974 \ldots \ldots \ldots \ldots$. . . . . . . . . . . . . . . . . . . . . . . 318

Grant Henning 1974 . . . . . . . . . . . . . . . . . . . . . . . 319

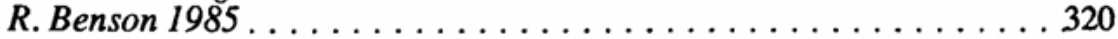

William F. Campbell $1989 \ldots \ldots$. . . . . . . . . . . . . . . . . 320

Ist das Barnabasevangelium unverfälscht? . . . . . . . . . . .322

Weitere Stellungnahmen . . . . . . . . . . . . . . . . 322

Übersetzungen des Barnabasevangeliums . . . . . . . . . . . 323

Englisch 1907: Lonsdale und Laura Ragg . . . . . . . . . . . . . . . . 323

Negative Westliche StellungNahmen zUM BaRnABaSEVANGeliUM . . . . 323

PoSITIVE WESTLICHE STELl UNGNAHMEN ZUM BARNABASEVANGELIUM . . . . . 323

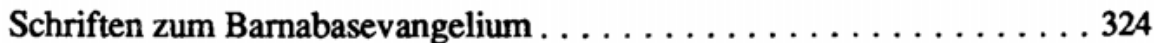

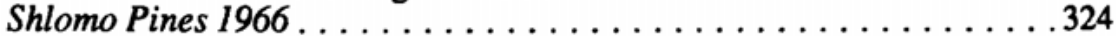

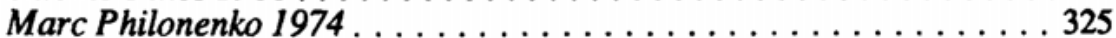

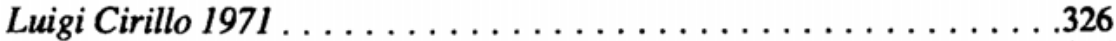

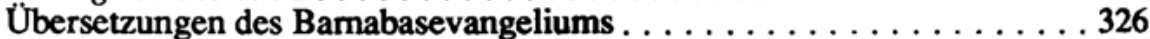

Französisch 1977: Luigi Cirillo und Michel Frémaux . . . . . . . . . 326

Niederländisch 1990: Hendrik Geels . . . . . . . . . . . . . . . 328

MUSLIMISCHE STELLUNGNAHMEN ZUR VERTEIDIGUNG DES

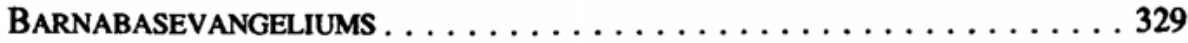

Schriften zum Barnabasevangelium . . . . . . . . . . . . . 329

Muhammad Muhammad Abû Zahra 1942 . . . . . . . . . . . . . . 329

Muhammad Muhammad Abû Zahras Position zum Christentum . . . 329

Abû Zahras Rückgriff auf die historisch-kritische Methode . . . . . . 330

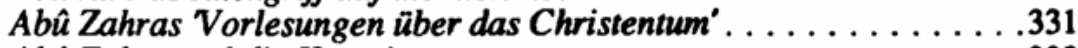

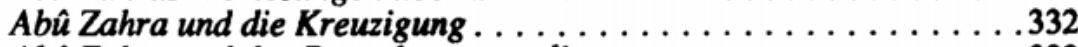

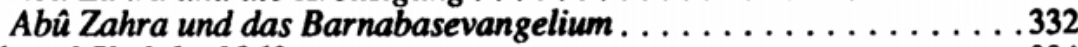

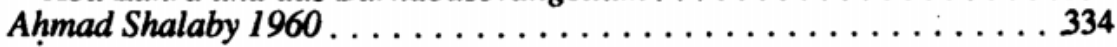


Mustafâ Hasan al-Bikrî $1966 \ldots \ldots \ldots \ldots$. . . . . . . . . . . . 338

Südafrika 1970er Jahre . . . . . . . . . . . . . . . . . . . . . . . . . . .338

Die Debatte um das Barnabasevangelium in The Pakistan Times'

1973/1974.

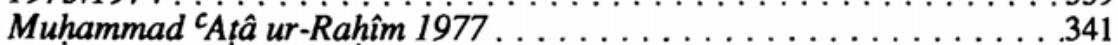

Cordoba 1977. . . . . . . . . . . . . . . . . . . . . . . . . . . . 342

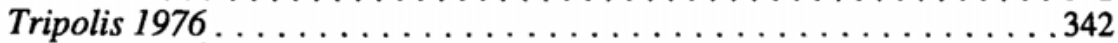

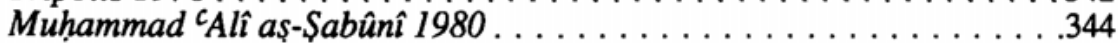

M. A. Yusseff $1985 \ldots \ldots \ldots \ldots \ldots \ldots$. . . . . . . . . . . . . . . . 344

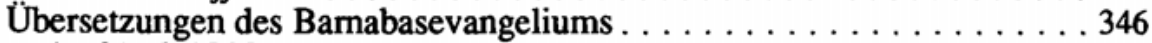

Arabisch 1908 . . . . . . . . . . . . . . . . . . . . . . . . . . 346

Englisch 1916 . . . . . . . . . . . . . . . . . . . . . . . 347

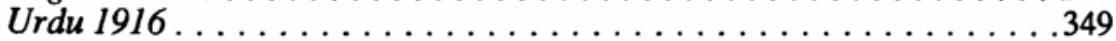

Persisch 1927. . . . . . . . . . . . . . . . . . . . .350

Indonesisch $1969 \ldots \ldots \ldots \ldots \ldots \ldots \ldots \ldots \ldots \ldots \ldots \ldots \ldots \ldots \ldots$

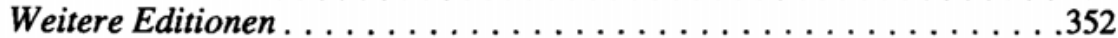

MUSLIMISCHE STELLUNGNAHMEN GEGEN DAS BARNABASEVANGELIUM . . . . . 353

Die Islamische Weltliga über das Barnabasevangelium: Muhammad

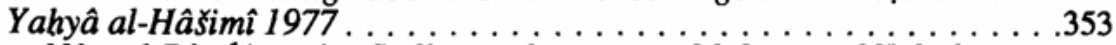

Nûr ad-Dîn 'Ammârs Stellungnahme gegen Muhammad Yahyâ

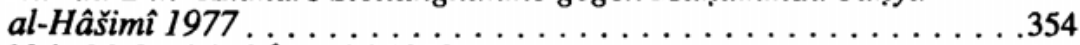

${ }^{c}$ Abbâs Mahmûd al ${ }^{c}$ Aqqâd $1959 \ldots \ldots \ldots \ldots \ldots \ldots \ldots \ldots \ldots \ldots$

Weitere muslimische Stimmen gegen das Barnabasevangelium . . . . .355

Muhammad Galâl Kišk 1985 . . . . . . . . . . . . . . . . . 356

Exkurs: Die christlich-muslimische Auseinandersetzung

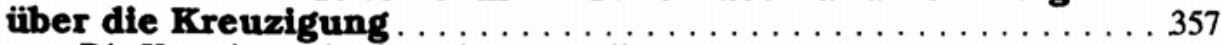

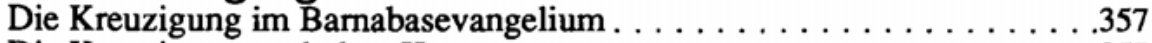

Die Kreuzigung nach dem Koran . . . . . . . . . . . . . . . . . 357

Muslimische Deutungen des 'Kreuzigungsverses' in Sure 4, $157 \ldots \ldots .358$

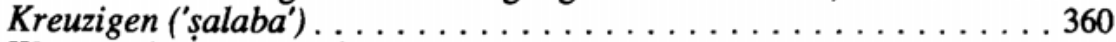

Wer wurde gekreuzigt? . . . . . . . . . . . . . . . . . 360

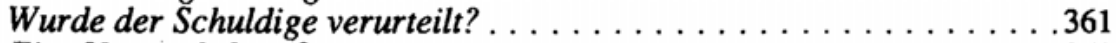

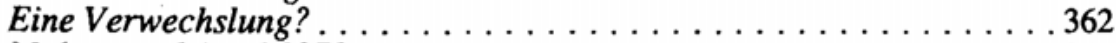

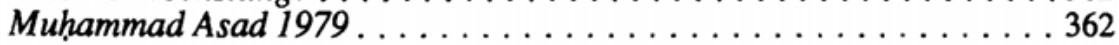

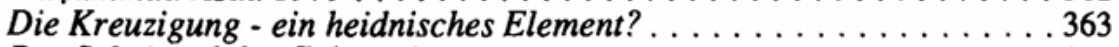

Der Scheintod des Gekreuzigten . . . . . . . . . . . . . . . . . . . 363

Die Unklarheit des Kreuzigungsverses . . . . . . . . . . . . . . 364

Ein 'fatwâ' der al-Azhar zum Tod Jesu $1942 \ldots \ldots \ldots \ldots \ldots \ldots . .365$

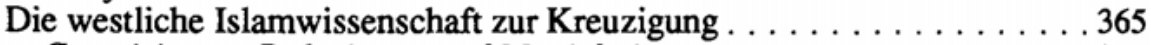

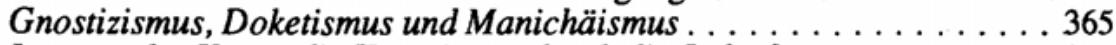

Leugnet der Koran die Kreuzigung durch die Juden? . . . . . . . . 366

Giulio Basetti-Sani 1977 . . . . . . . . . . . . . . . . . . . . . . . . .368

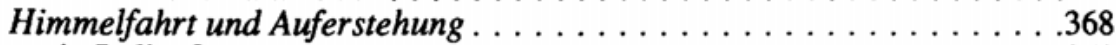

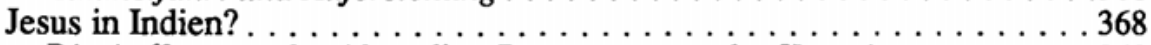

Die Auffassung der Ahmadîya-Bewegung von der Kreuzigung . . . . . 368

Alhaj A. D. Ajijola: 'The Myth of the Cross' 1975 . . . . . . . . . . 370

Weitere Befürworter der 'Jesus-in-Indien-Theorie' . . . . . . . . 370

Al-Haj Khwaja Nazir Ahmad: 'Jesus in Heaven on Earth' 1952 . . . . 371

Der europäische Rationalismus leugnet die Kreuzigung . . . . . . . . 372

David Friedrich Strauss verwirft die 'Ohnmachtstheorie' 1835/1889 _ . .374

Weitere Theorien . . . . . . . . . . . . . . . . . . . . . 375 
Das Neuverfassen von Evangelien . . . . . . . . . . . . . . . . . . 375

Das Neuverfassen von Evangelien auf muslimischer Seite: Ahmad

Shafaat 1979 . . . . . . . . . . . . . . . . . . . . . . . . 375

Das Neuverfassen von Evangelien auf europäischer Seite: Leo

Tolstoi I895/1896 . . . . . . . . . . . . . . . . . . . . . . . . . . . . .376

Die Kreuzigung im Zentrum muslimischer Veröffentlichungen im

20. Jahrhundert . . . . . . . . . . . . . . . . . . . . . . . . . . . . . . . 377

Offentliche Debatten über die Kreuzigung 1981 . . . . . . . . . . . . 377

Zeitgenössische muslimische Autoren über die Kreuzigung . . . . . . . 378

Muhammad Kâmil Husain $1954 \ldots \ldots \ldots \ldots . \ldots \ldots$

‘Abd al-Hamîd Gûda as-Sahhâr 1952 . . . . . . . . . . . . . . 379

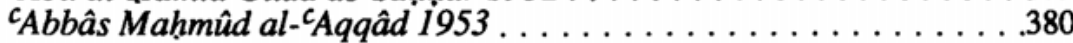

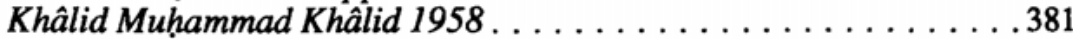

Kemal Demiral 1970 . . . . . . . . . . . . . . . . . . . . . . .381

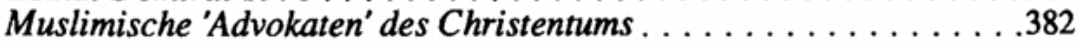

Zusammenfassung der Ergebnisse in Thesen: Die christlichmuslimische Kontroverse des 20. Jahrhunderts . . . . . . . . 383

Quellen, Literatur und Abkürzungen $\ldots \ldots \ldots \ldots \ldots \ldots \ldots 6$

A. Literatur zur christlich-muslimischen

Auseinandersetzung allgemein $\ldots \ldots \ldots \ldots \ldots \ldots \ldots \ldots$

B. Literatur zu Karl Gottlieb Pfander und Rahmatullâh

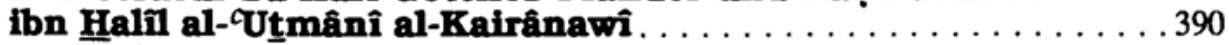

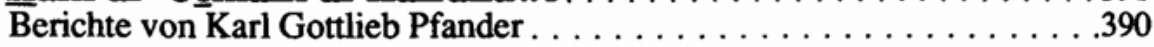

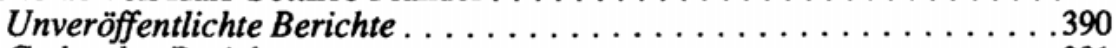

Gedruckte Berichte . . . . . . . . . . . . . . . . . . . .391

Veröffentlichte Werke von Karl Gottlieb Pfander . . . . . . . . . . . . . . .394

Veröffentlichte Werke von Rạ̣matullâh ibn Halîl al-CUțânî

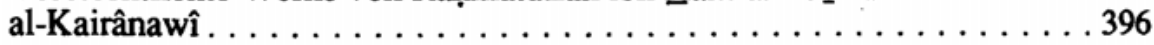

C. Guellen zur Fortsetzung der Kontroverse nach

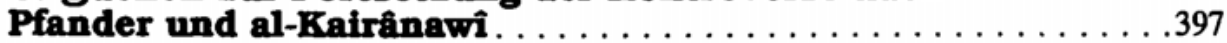

Unveröffentlichte Quellen . . . . . . . . . . . . . . . . . . . .397

Gedruckte Quellen . . . . . . . . . . . . . . . . . . . . . . . . . . . 399

Literatur zur Kontroverse zwischen Pfander und al-Kairânawî . . . . . . 401

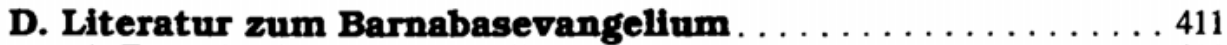

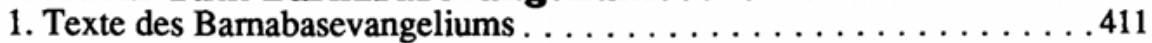

Handschriftliche Quellen. . . . . . . . . . . . . . . .411

Gedruckte Ausgaben des Barnabasevangeliums . . . . . . . . . 411

Behandelte Literatur zum Barnabasevangelium . . . . . . . . . . . 412

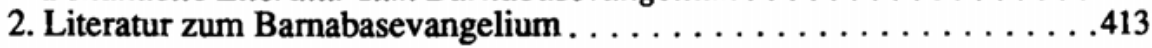

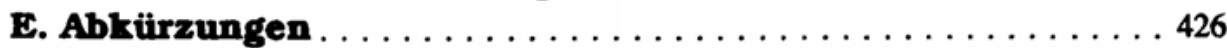

Index . . . . . . . . . . . . . . . . . . . . . . . 429 